\section{Simulation of Aquifer Remediation from Low-Permeable Lenses by Back-Diffusion Phenomenon}

Rudarsko-geološko-naftni zbornik

(The Mining-Geology-Petroleum Engineering Bulletin) UDC: 622.2

DOI: 10.17794/rgn.2021.5.6

Original scientific paper

\author{
Mojtaba Dehqani Tafti'; Faramarz Doulati Ardejani' ${ }^{2}$ Mohammad Fatehi Marji ${ }^{\text {; }}$ Yousef Shiri ${ }^{4}$ \\ ${ }^{1}$ Shahrood University of Technology, Faculty of Mining, Petroleum and Geophysics Engineering, Shahrood, Iran, \\ mojtaba.dehqani.t@gmail.com \\ ${ }^{2}$ School of Mining, College of Engineering, University of Tehran, Tehran, Iran, fdoulati@ut.ac.ir \\ ${ }^{3}$ Department of Mining and Metallurgical Engineering, Yazd University, Yazd, Iran, mohammad.fatehi@gmail.com \\ ${ }^{4}$ Shahrood University of Technology, Faculty of Mining, Petroleum and Geophysics Engineering, Shahrood, Iran, \\ yousefshiri@shahroodut.ac.ir
}

\begin{abstract}
Fluid flow in a dual permeable medium (DPM) is essential in solute transport in mining and aquifer studies. In this paper, water flushing into a contaminated DPM containing fine-grained lenses with different geometries was investigated with the Lattice Boltzmann Method (LBM). The LBM model used in this study was D2Q9 with a relaxation time of 1, a cohesion value of 3 for a fluid density of $1\left(\mathrm{mu}_{\mathrm{Lu}}{ }^{-3}\right)$. The saturated fluid in the DPM was a contaminant that usually stays in low permeable lenses and after flushing, it is leaked into the porous medium by a second fluid (water). This phenomenon is predominant when the displacing fluid has a lower concentration than the contaminated fluid. Diffusion and advection are the main mechanisms that control fluid flow in the porous medium. The results of the simulations showed: (1) advection controlled solute transport through the flushing phase, and back-diffusion occurred after the change in phase; (2) the lenses' geometry influenced the fluid flow pattern and the remediation process. As a result, aquifer remediation strategies based on the lenses' geometry and their permeability can help us select the appropriate environmental protection.
\end{abstract}

Keywords:

Lattice Boltzmann Method (LBM); contamination back-diffusion; low-permeable lenses; aquifer remediation; dual permeable medium (DPM).

\section{Introduction}

Fluid flow and its interaction with the solid surface of a porous material with complex structures has broad industrial applications, such as in oil and gas recovery, open and underground mines, and radioactive waste deposits (Kantzas et al., 2015; Medunić et al., 2018; Mohammadi et al., 2019; Veinović et al., 2020). Contaminant retention in fine-grained lenses is a challenging problem that pollutes the aquifer for a long time, and its removal is essential for human life. Prediction of the contaminants' dispersion in the groundwater flow system and understanding the procedure to reduce the contaminants are controversial topics covered by several researchers (Stroo et al., 2003; National Research Council, 2005; Sale and Newell, 2010; Kopić et al., 2016; Barešić et al., 2020; Geng et al., 2021).

Aquifer restoration time in a real site is strongly dependent on contaminant type, fluid properties, and many other parameters, such as mineralogy and geometry of

Corresponding author: Faramarz Doulati Ardejani fdoulati@ut.ac.ir grains, pore size distribution, open and closed fracture, and so forth. Diffusion, one of the main processes causing contaminant movement, depends on the concentration gradient and surface area of the contamination (Pinder and Celia, 2006). The back-diffusion phenomenon was studied numerically and physically in some specific situations by many researchers (Dentz and Berkowitz, 2003; Chapman and Parker, 2005; Parker et al., 2008; Herrera et al., 2010). In the transport of contaminants, back-diffusion is a phenomenon that preserves contamination in the porous medium for a long time. This phenomenon occurs where low permeable lenses are placed between sandy aquifers. This issue was addressed in some studies (Wilson, 1997; Liu and Ball, 2002; Parker et al., 2004; Chapman and Parker, 2005; Safari et al., 2020). Fluid flow in the DPM is preferential in both low and high permeable domains. Other factors that influence the flux of displacing fluid within the low-permeable lenses are geometry and surface area between the low and high permeable zones (Dimmen et al., 2020).

Studying fluid flow through a porous medium by experimental setup is a costly and time-consuming proce- 
dure. Computational fluid dynamics (CFD) are used as a valuable tool to understand the physics of fluids and their interaction with other fluids and solid matrices (Homayoon et al., 2011; Safari et al., 2017, 2020; Mohamad, 2019). CFD is categorized into two classes. The first class is the simulation by considering macro variables and solving continuity equation by finite difference, finite element, and finite volume methods. These methods are based on the discretization of Navier-Stokes equations assuming a continuous flow medium (Mohamad, 2019). The second class is the simulation in mesoscale and microscale. The LBM is one of these techniques for simulation of fluid flow in mesoscale (McNamara and Zanetti, 1988). The LBM is an effective numerical method to observe the diffusion process over a period of time in a mesoscale or centimetre scale. The main advantages of using the LBM are: (1) high speed performance; (2) parallel computation; (3) simple implementation without solving differential equations; (4) pore-scale flow behaviour in complex structures and boundary conditions; and (5) multi-phase and incompressible fluid flow simulation. On the other hand, LBM has some disadvantages, such as: (1) not straightforward to couple the LBM with other mechanical transfer systems; and (2) numerical stability is not guaranteed, especially for fluids with high density and high viscosity (Zhang, 2011; Mohamad, 2019). Some relevant research for the current study regarding the LBM showed its capability to determine permeability in a rough fracture (Eker and Akin, 2006), to study the groundwater flow and solute transport in a karstic porous medium (Sukop et al., 2008), to evaluate the permeability and non-Darcy flow in South Florida limestone (Sukop et al., 2013), to predict the permeability of real and synthetic porous media (Boek and Venturoli, 2010), to study the effects of stress on relative permeability (Huang et al., 2021), and to analyse the effect of heterogeneous complex porous media on fluid flow pattern (Shiri et al., 2018; Shiri and Hassani, 2021; Shiri and Shiri, 2021).

The present study was aimed at investigating water flushing in contaminated fine-grained lenses with different geometries and low permeability by the LBM. Moreover, the contribution of advection and back-diffusion process was investigated in a time period, in which four thin permeable fine-grained lenses pollute an aquifer and change the water quality.

\section{Material and Methods}

\subsection{Numerical method}

For the first time, the LBM was derived from the lattice-gas automata (LGA) as a mesoscale method (Pulvirenti and Tirozzi, 1973). Both the LGA and the LBM are between two macro-scale Navier-stocks models and microscopic dynamic models. Instead of solving the Na-

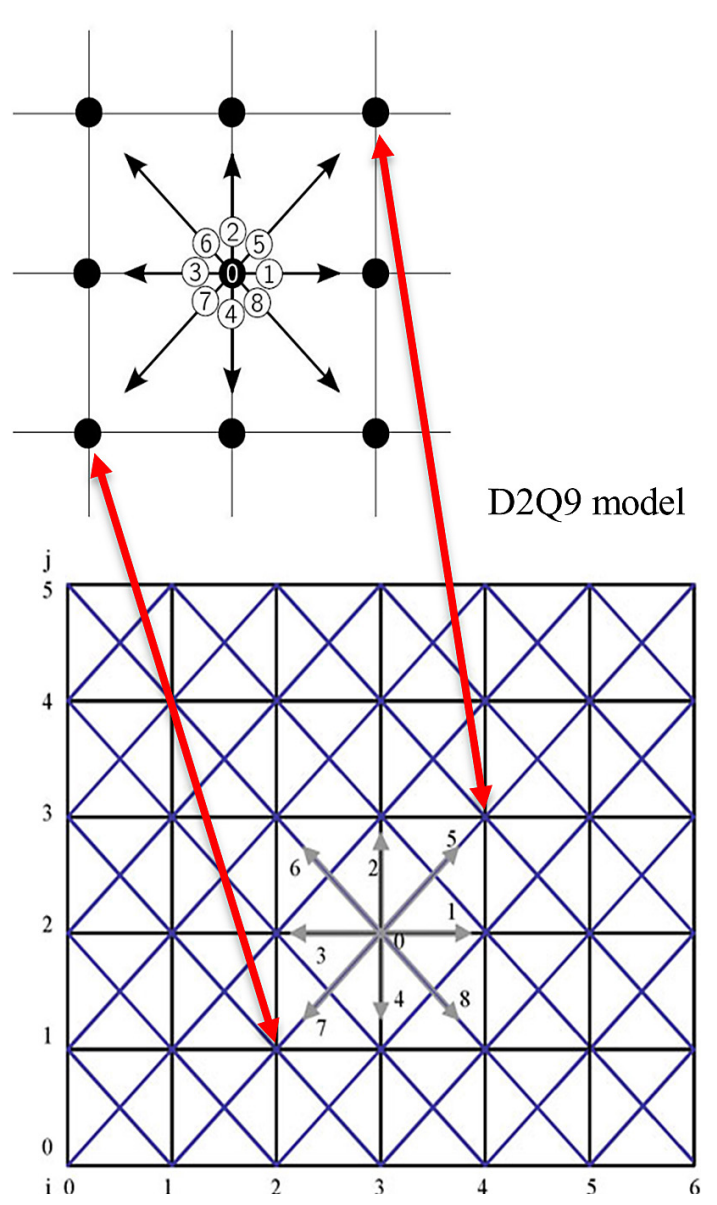

Figure 1: Lattice arrangements for 2D LBM model with nine velocity vectors, modified from Mohamad (2019)

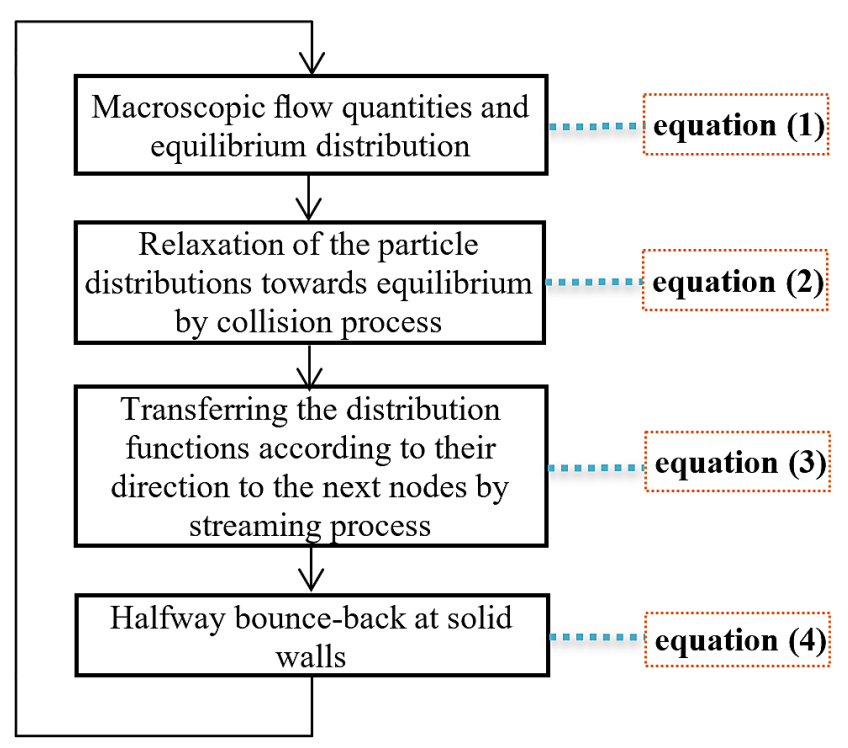

Figure 2: Time marching procedure of pseudo-potential LBM algorithm and relevant equations, adapted from Mohamad (2019)

vier-Stokes equations, the LBM solves the Boltzmann equation (Navier-stocks equation can be derived from the Boltzmann equation). Collision and streaming are two fundamental procedures of the LBM. 
In this study, the D2Q9 LBM model (see Figure 1) with the Bhatnagar-Gross-Krook-Welander (BGKW) approximation for the collision process was used (see Figure 2). The Lattice Boltzmann algorithm was introduced by Shan and Chen (Shan and Chen, 1993) and a flowchart of the model is shown in Figure 2.

$$
\begin{gathered}
\rho(\vec{x}, t)=\sum_{i=0}^{N} f_{i}^{\text {in }}(\vec{x}, t) \\
\rho(\vec{x}, t) \vec{u}(\vec{x}, t)=\sum_{i=0}^{N} \vec{e}_{i} f_{i}^{\text {in }}(\vec{x}, t) \\
f_{i}^{\text {eq }}(\vec{x}, t)=\rho \omega_{i}\left[1+\frac{3}{c^{2}}\left(\vec{e}_{i} \cdot \vec{u}\right)+\frac{9}{2 c^{4}}\left(\vec{e}_{i} \cdot \vec{u}\right)^{2}-\frac{3}{2 c^{2}}(\vec{u} \cdot \vec{u})\right] \\
f_{i}^{\text {out }}(\vec{x}, t)=f_{i}^{\text {in }}(\vec{x}, t)-\frac{1}{\tau}\left[f_{i}^{\text {in }}(\vec{x}, t)-f_{i}^{\text {eq }}(\vec{x}, t)\right] \\
f_{i}^{\text {in }}\left(x+\vec{e}_{i}, t+\Delta t\right)=f_{i}^{\text {out }}(\vec{x}, t)=f_{i}^{\text {in }}(\vec{x}, t) \rightarrow x \in \text { wall }(4) \\
e_{i}= \begin{cases}(0,0) \\
(\cos [(i-1) \pi / 2], \sin [(i-1) \pi / 2]) \\
\sqrt{2}(\cos [(i-5) \pi / 2+\pi / 4], \sin [(i-5) \pi / 2+\pi / 4]) & \mathrm{i}=5,6,7,8\end{cases}
\end{gathered}
$$

Where:

$$
\begin{aligned}
& i \quad-\text { index of velocity components, } \\
& t \quad-\text { time (ts), } \\
& x \quad \text { - node position, } \\
& f_{i}(x, t) \text { - distribution function of fluid, } \\
& \rho^{k} \quad-\text { density of each phase }\left(\mathrm{gr} / \mathrm{lu}^{3}\right) \text {, } \\
& e_{i} \quad-\text { identity vector that indicates the velocity } \\
& u \quad-\text { overall velocity (lu/ts), } \\
& w_{i} \quad-\text { weight of any velocity component, } \\
& f^{(e q)}(x, t) \text { - the equilibrium state of each fluid distribu- } \\
& \tau \quad-\text { the relation time for each component to } \\
& \Delta x \quad \text { - length of lattices (lu), } \\
& \Delta t \quad \text { - time step (ts). }
\end{aligned}
$$

Fluid properties in the LBM models are introduced by their velocity distribution in the lattice network (Sukop and Thorne, 2006). The method can be briefly described as follows: first, variables are defined and the porous medium is inserted by assuming a value of 1 for solid nodes and a value of 0 for fluid nodes and then, density distributions are initialized. Second, the fluid equilibrium velocity distribution is defined. In each node, there are nine velocity components in the D2Q9 Model that are updated in the time marching process based on the interaction between neighbourhood nodes. The direction of any velocity component in a lattice node and their weights can be assigned with Equation (5) and Equation (6), respectively (Guo et al., 2000). Third, the collision process is done by considering the previous density and velocity distributions of the fluid components of all nodes. Fourth, the energy of the fluids in any lattice node is transferred by streaming operation. Fifth, boundary conditions are applied. Finally, macroscopic variables like density and velocity are calculated in each node.

\subsection{Porous media}

Fine-grained lenses with different geometries in a sandy aquifer are shown in Figure 3. This model was investigated by several researchers. Firstly, a sand pack $(1.07 \times 0.03 \times 0.84 \mathrm{~cm})$ laboratory experiment with four fine-grained lenses was examined. The model was saturated with a tracer monitoring flushing of the model by clean water (Doner, 2008). Then, this model was simulated to validate the results by high-resolution numerical models by Hydro Geosphere, FEFLOW, MODFLOW/ MT3DMS (Chapman et al., 2012). Also, a semi-analytical method was used to investigate similar behaviour in a 2D model with a fine-grained lens in a high permeable zone (Muskus and Falta, 2018). In the current study, parameters were adjusted with the experimental and numerical investigation (Doner, 2008; Chapman et al.,

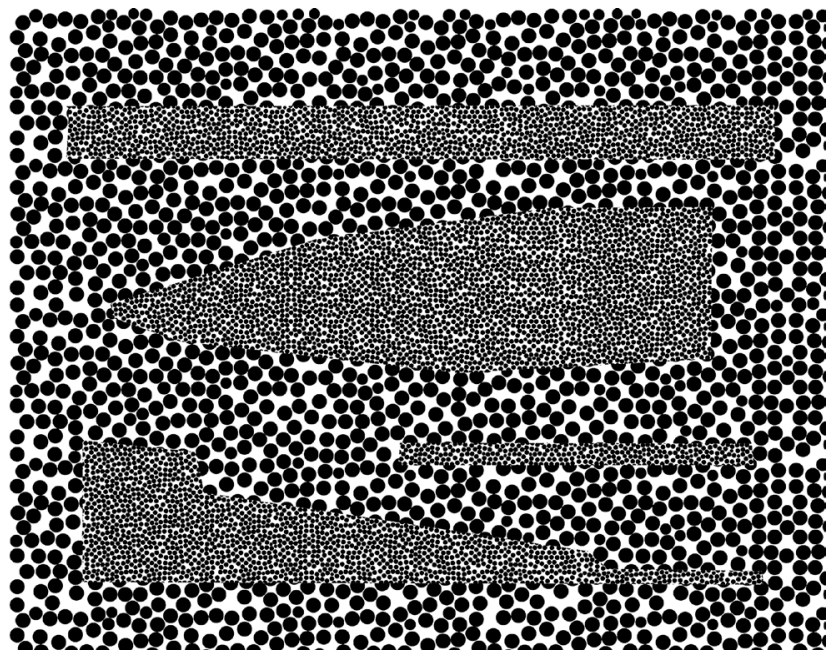

Figure 3: Fine-grained lenses with different geometries in a sandy aquifer, fluids flow from the left boundary towards the right boundary and the top and bottom boundaries are sealed. The host sand porous medium has an average grain size of $1000 \mu \mathrm{m}$ and the fine-grained lenses have average grain sizes of $300 \mu \mathrm{m}$. 
Table 1. LBM parameters used in all simulations

\begin{tabular}{|l|l|l|l|l|l|}
\hline LBM model & $\begin{array}{l}\text { Lattice } \\
\text { dimension }\end{array}$ & $\begin{array}{l}\text { Relaxation time } \\
\text { (dimension less value) }\end{array}$ & $\begin{array}{l}\mathbf{G}_{\text {adhesion }} \\
\text { (dimension less value) }\end{array}$ & $\begin{array}{l}\mathbf{G}_{\text {cohesion }} \text { (dimension } \\
\text { less value) }\end{array}$ & $\begin{array}{l}\text { Density } \\
\left(\mathbf{m u}_{\text {Lu }}{ }^{-3}\right)\end{array}$ \\
\hline D2Q9 & $1580 \times 1240$ & 1 & 0 & 3 & 1 \\
\hline
\end{tabular}

a)

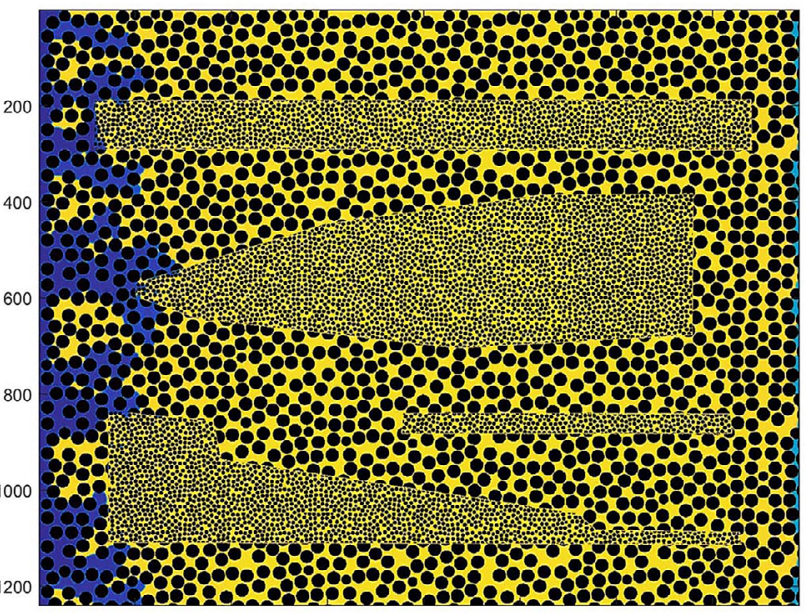

200

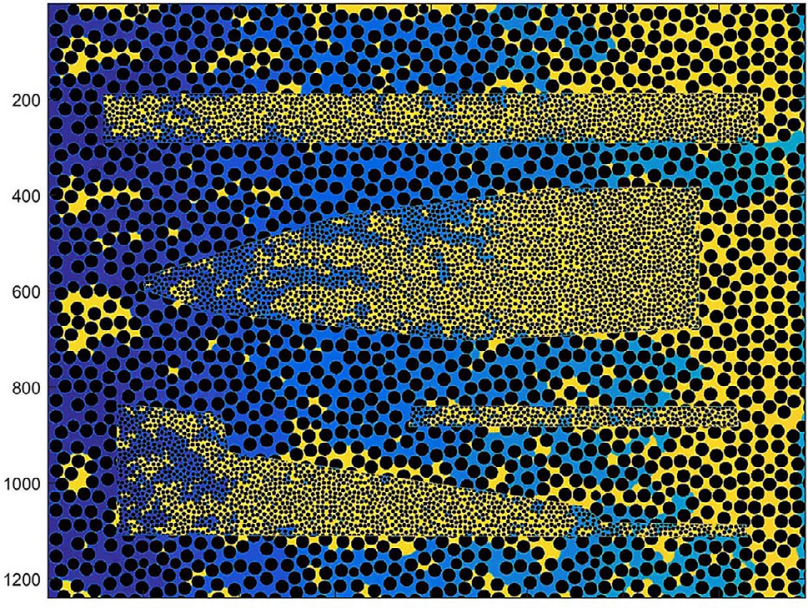

200

400

600

800

1000

1400

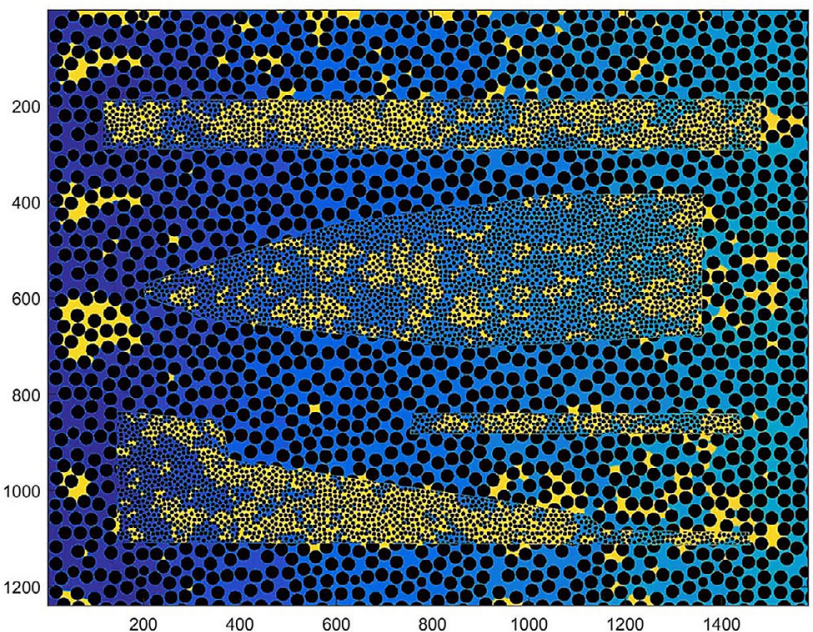

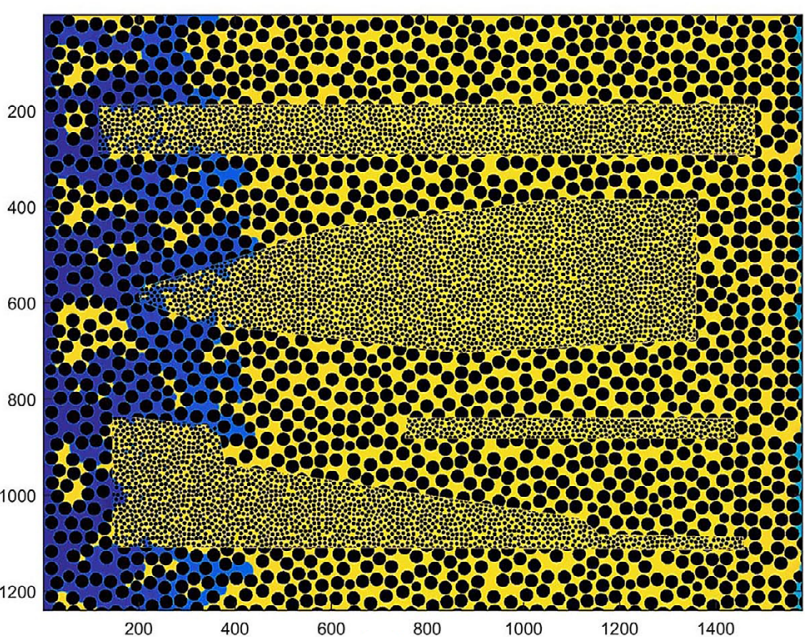

b)
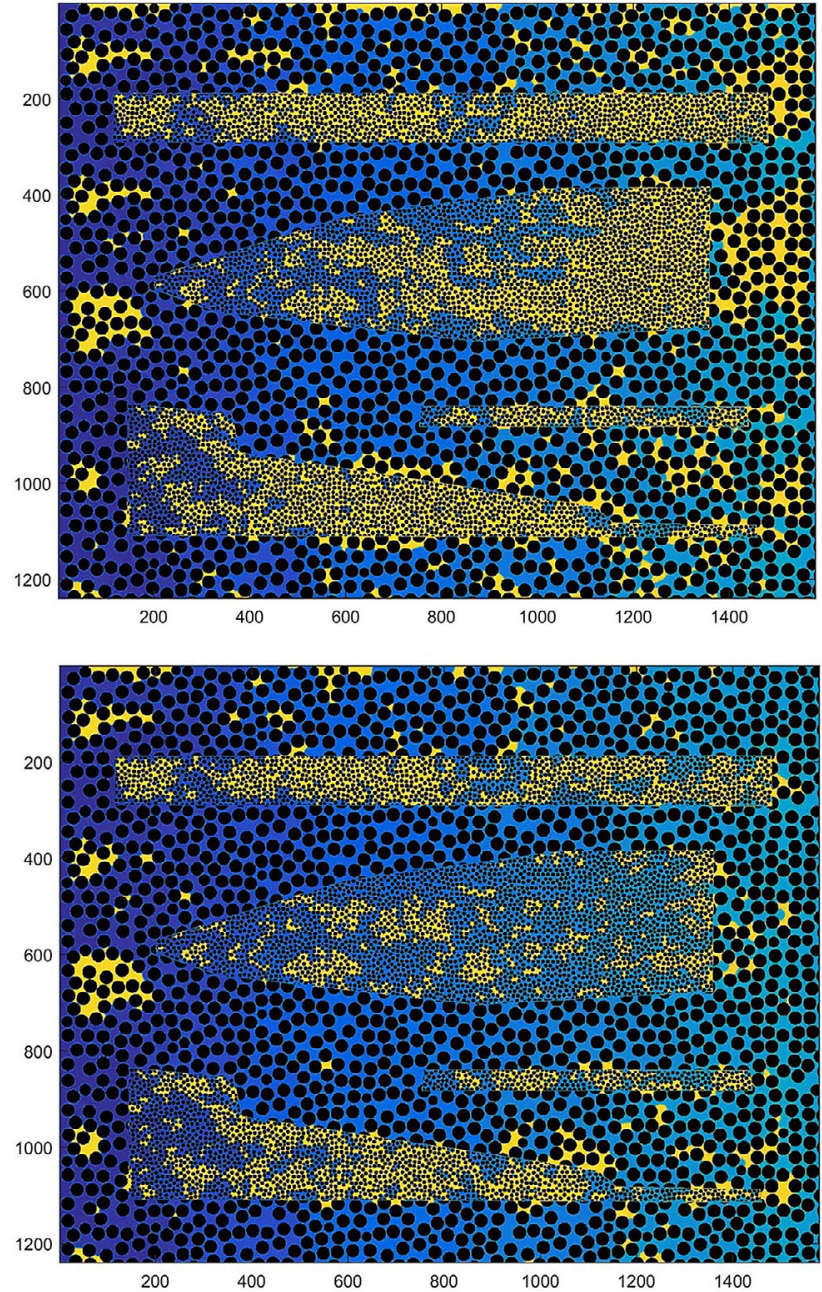

f)

Figure 4: Back-diffusion process in a dual permeable medium in the form of fine-grained lenses within the host sand medium with a lower pressure gradient, a) saturation at time steps of 20 'ooo, b) saturation at time steps of 400 'ooo,

c) saturation at time steps of 2'660'ooo, d) saturation at time steps of 3'840'ooo, e) saturation at time steps of 6'820'0oo,

f) saturation at time steps of $75^{\prime 20}$ 'ooo 


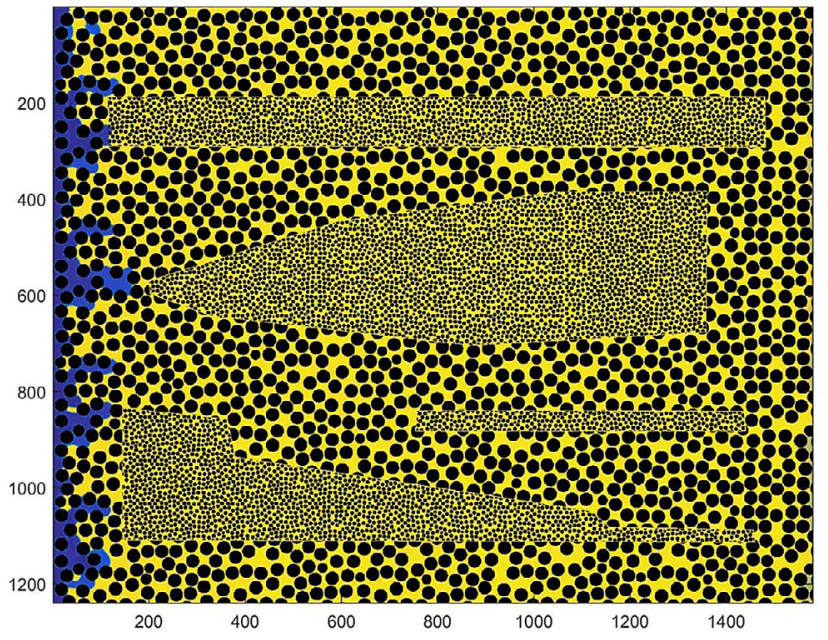

a)

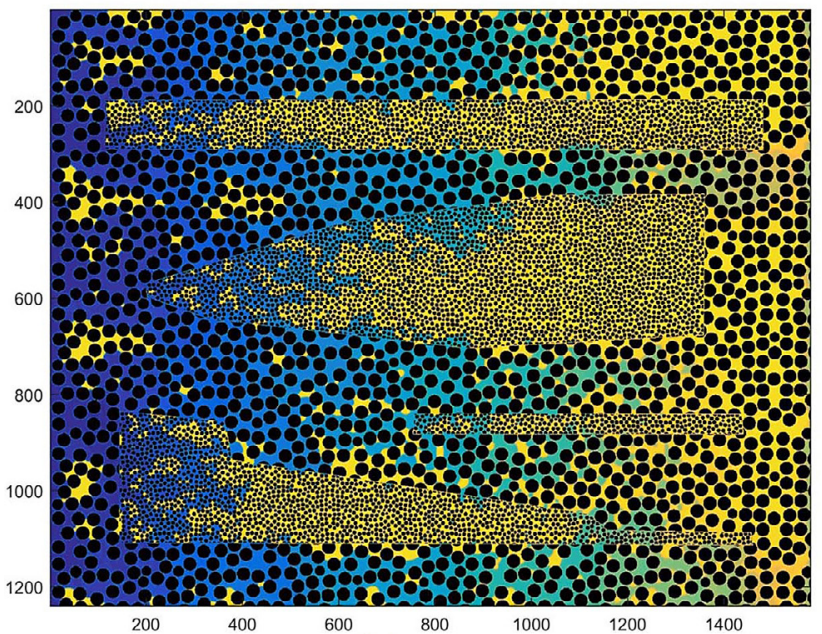

c)

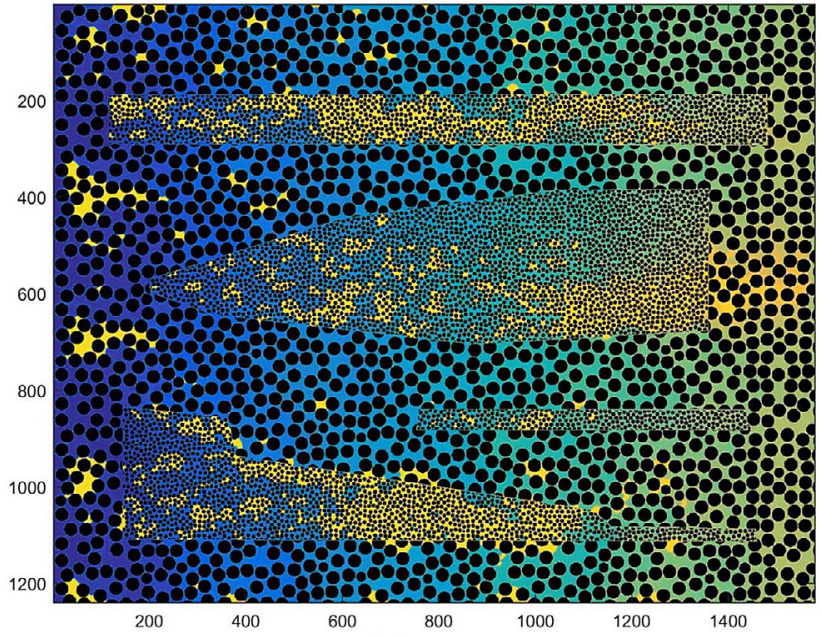

e)

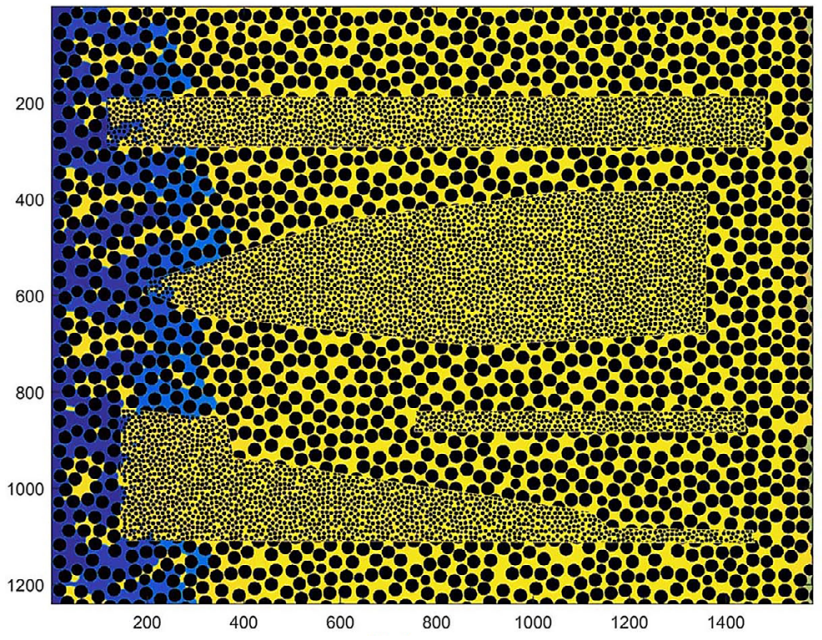

b)

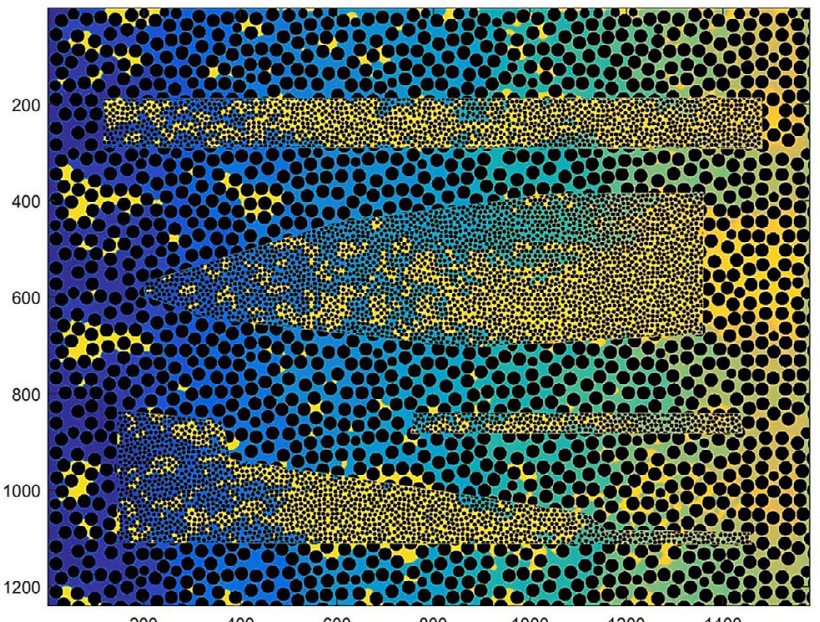

d)

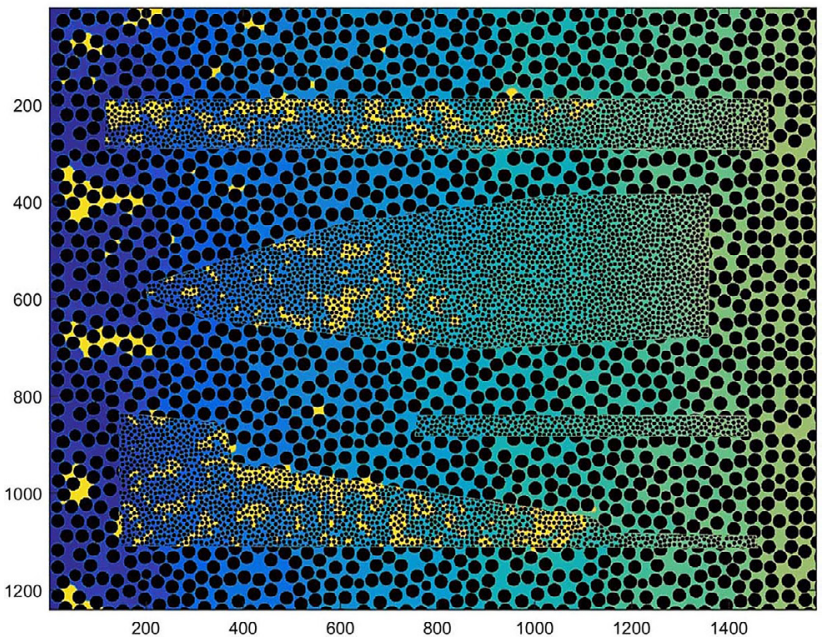

f)

Figure 5: Back-diffusion process in a dual permeable medium in the form of fine-grained lenses within the host medium (sand) with a higher pressure gradient, a) saturation at time steps of 20'0oo, b) saturation at time steps of 200'ooo,

c) saturation at time steps of 1'060'ooo, d) saturation at time steps of 1'540'ooo, e) saturation at time steps of 2'060'000,

f) saturation at time steps of 3'480'ooo 


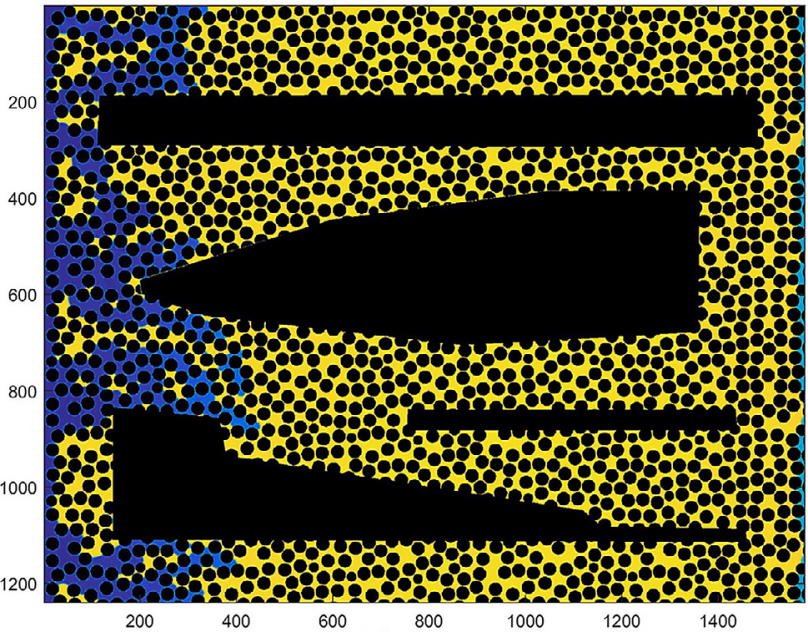

a)

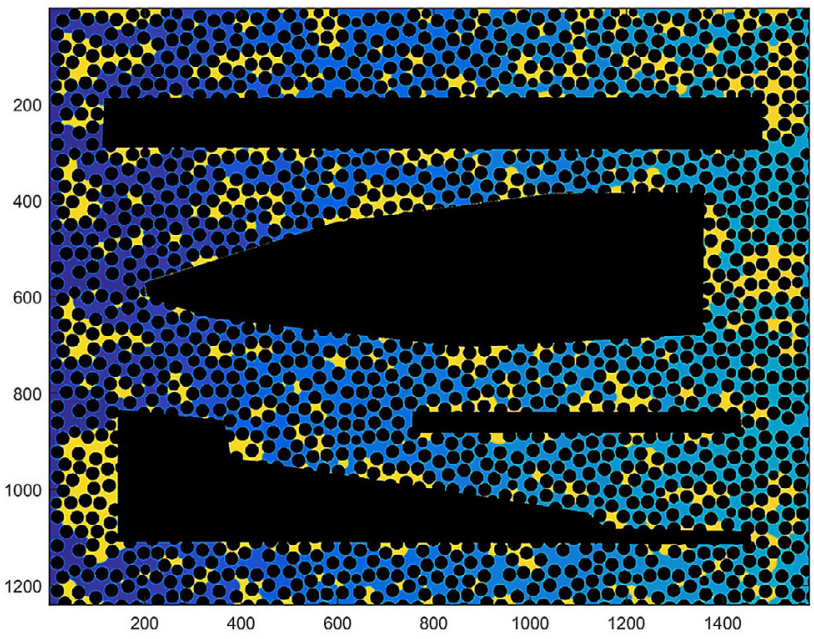

c)

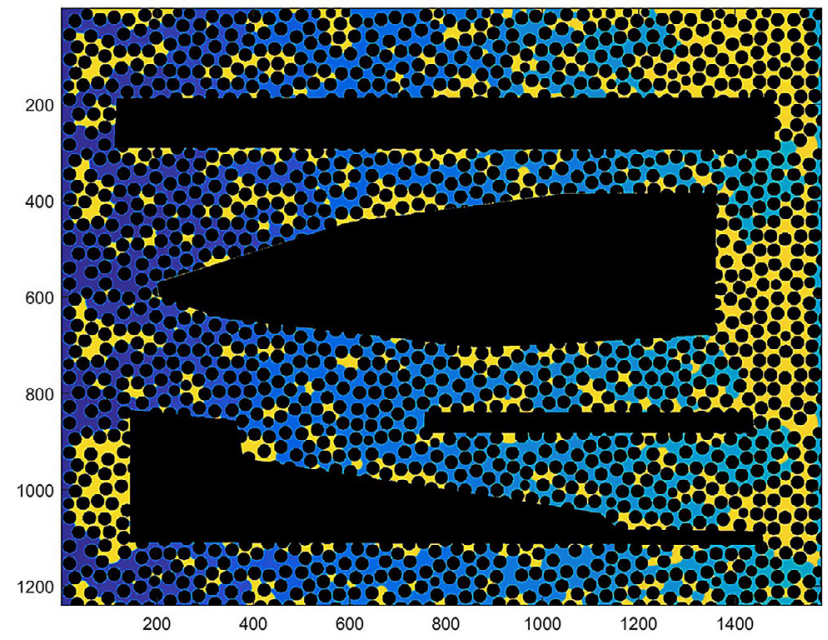

b)

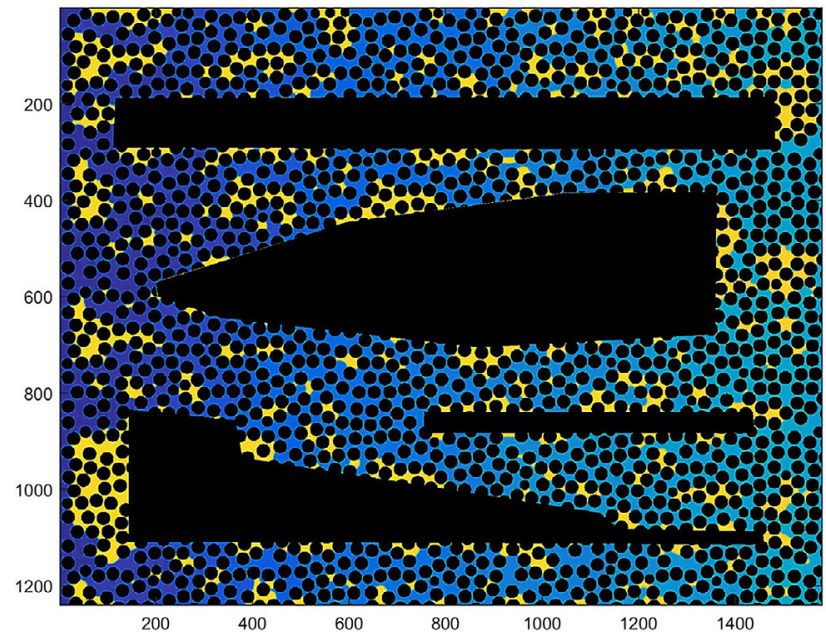

d)

Figure 6: Effect of the geometry of impermeable lenses on the fluid flow streamlines in a porous medium containing impermeable lenses, a) saturation at time steps of 760'ooo, b) saturation at time steps of 3'420'0oo, c) saturation at time steps of 4'340'0oo, d) saturation at time steps of 4'560'000

2012). The model has vertical and horizontal dimensions of 4.2 and $5.35 \mathrm{~cm}$, respectively. The average grain size of sand was $1000 \mu \mathrm{m}$, and it was $300 \mu \mathrm{m}$ for finegrained lenses. The distributions of grains in the porous medium were random, and the porosity was 0.45 . Besides, for a better understanding of the effects of the geometries of the lenses on fluid flow streamlines, a single porous medium with lenses without porosity and permeability was examined.

\subsection{Initial values and boundary conditions}

Proper assigning boundary conditions (BCs) is essential in the LBM. There are various types of BCs, including non-slip $\mathrm{BC}$, periodic $\mathrm{BC}$, velocity $\mathrm{BC}$, pressure $\mathrm{BC}$, and open BC. In this study, halfway non-slip BC was specified on solid surfaces. As a result, when fluid particles collide with the solid node the fluid velocity components are reversed (Sukop and Thorne, 2006). Constant pressure BCs presented by Huang for a two-component flow prob- lem (Huang, 2016) was used for the left inlet and the right outlet in all simulations. The LBM parameters used in the current simulations are given in Table $\mathbf{1 .}$

\section{Results and Discussion}

The back-diffusion process in DPM (see Figure 3) with two different hydrostatic pressures are shown in Figure 4 and Figure 5. DPM contains four fine-grained lenses within the host sand porous medium. In all simulations, firstly assumed that the porous medium was fully saturated with the contaminated fluid (the yellow colour in Figure 4, Figure 5, and Figure 6). For a better understanding of the heterogeneity effects on the advection and diffusion transport mechanisms, two models including a dual permeable medium (DPM) (see Figure 4, Figure 5) and a porous medium containing impermeable lenses (PMIL) (see Figure 6) were investigated. The effect of flow rate on the DPM model was investi- 
gated by changing the pressure gradient (see Figure 4, Figure 5). PMIL simulation (see Figure 6) was run in the same pressure gradient as in Figure 4.

As shown in Figure 4(a, b, c) and Figure 5(a, b, c), before the breakthrough, an increase in the pressure gradient improved contaminant removal from the finegrained lenses. Among different lenses, rectangular lenses have more capacity for solute (contaminant) retention. After the breakthrough, solute retention of the lower pressure gradient model (see Figure 4(d, e, f)) was greater than the higher pressure gradient model (see Figure 5(d, e, f)). Besides the pressure gradient, shape (geometry) and volume of fine-grained lenses were important and affected the contaminant preservation. A comparison between the DPM (see Figure 4(a, b, c)) and the PMIL (see Figure 6(a, b)) under the same pressure gradient showed that the permeability heterogeneity affected the fluid front. The fluid front in the PMIL was more stable with a smaller fingering pattern than the DPM. Hence, the contaminant in PMIL left the entire porous medium better than the DPM model.

After the breakthrough (see Figure 4(d, e, f) and Figure $6(\mathbf{c}, \mathbf{d})$ ), the results showing bubble trapping phenomenon was more prevalent in the PMIL than in the DPM. Also, fine-grained lenses act as contaminant storage systems that polluted the downstream for a long time.

The effects of the pressure gradient and permeability heterogeneity on the concentration breakthrough curve (BTC) of the DPM and the PMIL are shown in Figure 7. In BTC, the horizontal axis is time (time step, ts), and the vertical axis is the relative concentration of contaminant leaving the porous medium (dimensionless unit). The blue curve with circle points represents the DPM with a low-pressure gradient, and the red curve with square points denotes the DPM with a high-pressure gradient. The black curve with star points belongs to the PMIL with a low-pressure gradient.

As can be seen in Figure 7, by decreasing the pressure gradient, the contaminant formed a long tail and left the porous medium smoothly (blue circle in comparison to the red square). The formation of a long tail of plume and back-diffusion process was validated by numerical, experimental, and analytical results of previous studies (Parker et al., 2008; Chapman et al., 2012; Muskus and Falta, 2018). After removal of the source of contamination, the contamination was supported by the tailing effects. So, the first stage of the curve indicated the flushing zone, and the second stage was about the backdiffusion phase, in which the effluent from fine-grained lenses diffused to the high permeable region and polluted downstream water. The deflection points in the BTC (see Figure 7) was used for detecting the phase changing from the flushing phase to the back-diffusion phase. This point occurred for a high-pressure gradient when only 30 percent of the pollutant was removed from the porous medium. However, it occurred in the 85 percent

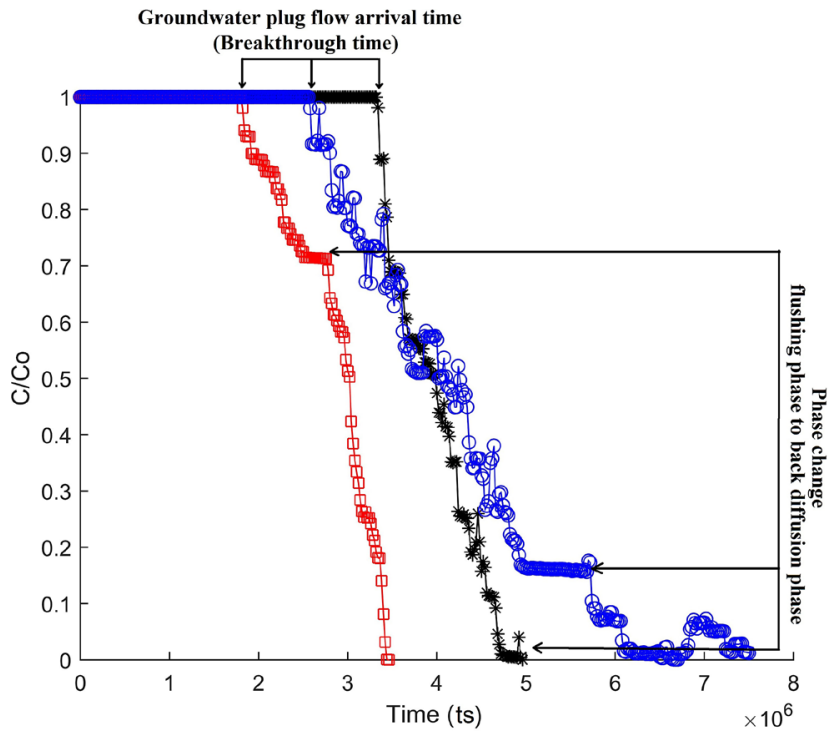

Figure 7: Breakthrough curve: a dual permeable medium with a low-pressure gradient (blue circle), a dual permeable medium with a high-pressure gradient (red square), a porous medium containing impermeable lenses with a low-pressure gradient (black star)

pollutant removal for the low-pressure gradient. For the PMIL, there was no back-diffusion and only the flushing phase was observed. As a conclusion, the LBM simulation results were comparable, and it was a good tool for studying effluent tracking in a heterogeneous porous medium. The limitations of the current study were the two dimensional LBM, and also the numerical instability due to high velocity, high density, and high viscosity contrast.

\section{Conclusions}

In this study, four fine-grained contaminated lenses were flushed with clean water. Contaminant removal from these lenses were investigated numerically by the D2Q9 model of the LBM with a relaxation time of 1, a cohesion value of 3 , and a fluid density of $1\left(\mathrm{mu}^{2} \mathrm{Lu}^{-3}\right)$. The long-tail plume formation and the back-diffusion process in these lenses were verified by numerical, experimental, and analytical results of previous studies. The results showed: (1) a high-pressure gradient leads to strong advection force and causes partial contaminant removal; (2) fine-grained lenses act as contaminant storage systems that gradually polluted the downstream by the back-diffusion process; (3) investigation of the advection and back-diffusion processes showed that the advection controlled the solute transport through the flushing phase, and back-diffusion was dominant after the phase was changed; (4) the flow pathway through four lenses with different geometries showed the structure of lenses influenced the fluid flow pattern and the remediation process. As a practical implication, using conceptual and numerical models to examine a real site 
aquifer remediation can help us to find the best strategies for environmental protection.

\section{Nomenclature}

$i \quad$ index of velocity components

$t$ time (ts)

$x \quad$ node position

$f_{i}(x, t)$ distribution function of fluid

$\rho^{k} \quad$ density of each phase $\left(\mathrm{gr} / \mathrm{lu}^{3}\right)$

$e_{i} \quad$ identity vector that indicates the velocity direction of different components in a lattice node

$u \quad$ overall velocity (lu/ts)

$w_{i} \quad$ weight of any velocity component

D2Q9 two dimensions nine components LBM

\section{References}

Barešić, J., Parlov, J., Kovač, Z., Sironić, A. (2020): Use of nuclear power plant released tritium as a groundwater tracer. Rudarsko Geolosko Naftni Zbornik, 35, 1, 25-34. doi: 10.17794/rgn.2020.1.3

Boek, E. S., Venturoli, M. (2010): Lattice-Boltzmann studies of fluid flow in porous media with realistic rock geometries. Computers and Mathematics with Applications, 59, 7, 2305-2314. doi: 10.1016/j.camwa.2009.08.063

Chapman, S. W., Parker, B. L. (2005): Plume persistence due to aquitard back diffusion following dense nonaqueous phase liquid source removal or isolation. Water Resources Research, 41, 12, 1-16. doi: 10.1029/2005WR004224

Chapman, S. W., Parker, B. L., Sale, T. C., Doner, L. A. (2012): Testing high resolution numerical models for analysis of contaminant storage and release from low permeability zones. Journal of Contaminant Hydrology, 136-137, 106116. doi: 10.1016/j.jconhyd.2012.04.006

Dentz, M., Berkowitz, B. (2003): Transport behavior of a passive solute in continuous time random walks and multirate mass transfer. Water Resources Research, 39, 5. doi: 10.1029/2001WR001163

Dimmen, V., Rotevatn, A., Nixon, C. W. (2020): The relationship between fluid flow, structures, and depositional architecture in sedimentary rocks: An example-based overview. Geofluids, 2020, 1-19. doi: 10.1155/2020/3506743

Doner, L. A. (2008): Tools to resolve water quality benefits of upgradient contaminant flux reduction. Colorado State University, $180 \mathrm{p}$.

Eker, E., Akin, S. (2006): Lattice Boltzmann simulation of fluid flow in synthetic fractures. Transport in Porous Media, 65, 3, 363-384. doi: 10.1007/s11242-005-6085-4

Geng, Z., Liu, B., Li, G., Zhang, F. (2021): Enhancing DNAPL removal from low permeability zone using electrical resistance heating with pulsed direct current. Journal of Hazardous Materials, 413, 125455. doi: 10.1016/j.jhazmat.2021.125455
Guo, Z., Shi, B., Wang, N. (2000): Lattice BGK model for incompressible Navier-Stokes equation. Journal of Computational Physics, 165, 1, 288-306. doi: 10.1006/jcph. 2000.6616

Herrera, P. A., Valocchi, A. J., Beckie, R. D. (2010): A multidimensional streamline-based method to simulate reactive solute transport in heterogeneous porous media. Advances in Water Resources, 33, 7, 711-727. doi: 10.1016/j.advwatres.2010.03.001

Homayoon, A., Isfahani, A. H. M., Shirani, E., Ashrafizadeh, M. (2011): A novel modified lattice Boltzmann method for simulation of gas flows in wide range of Knudsen number. International Communications in Heat and Mass Transfer, 38, 6, 827-832. doi: 10.1016/j.icheatmasstransfer.2011.03.007 UR

Huang, J., Xiao, F., Labra, C., Sun, J., Yin, X. (2021): DEMLBM simulation of stress-dependent absolute and relative permeabilities in porous media. Chemical Engineering Science, 239, 116633. doi: 10.1016/j.ces.2021.116633

Huang, J. (2016): Pore-scale simulation of multiphase flow using lattice Boltzmann method: developments and applications. Colorado School of Mines. Arthur Lakes Library, $99 \mathrm{p}$.

Kantzas, A., Jonathan, B., Taheri, S. (2015): Fundamentals of fluid flow in porous media. PERM Inc, Calgary, $336 \mathrm{p}$.

Kopić, J., Loborec, J., Nakić, Z. (2016): Hydrogeological and hydrogeochemical characteristics of a wider area of the regional well field eastern Slavonia - Sikirevci. Rudarsko Geolosko Naftni Zbornik, 31, 3, 47-66. doi: 10.17794/ rgn.2016.3.4

Liu, C., Ball, W. P. (2002): Back diffusion of chlorinated solvent contaminants from a natural aquitard to a remediated aquifer under well-controlled field conditions: Predictions and measurements. Ground Water, 40, 2, 175-184. doi: 10.1111/j.1745-6584.2002.tb02502.x

McNamara, G. R., Zanetti, G. (1988): Use of the boltzmann equation to simulate lattice-gas automata. Physical Review Letters, 61, 20, 2332-2335. doi: 10.1103/PhysRevLett.61.2332

Medunić, G., Kuharić, Ž., Fiket, Ž., Bajramović, M., Singh, A. L., Krivohlavek, A., Kniewald, G., Dujmović, L. (2018): Selenium and other potentially toxic elements in vegetables and tissues of three non-migratory birds exposed to soil, water, and aquatic sediment contaminated with seleniferous raša coal. Rudarsko Geolosko Naftni Zbornik, 33, 3, 53-62. doi: 10.17794/rgn.2018.3.6

Mohamad, A. A. (2019): Lattice Boltzmann method: fundamentals and engineering applications with computer codes. Springer, London, $240 \mathrm{p}$.

Mohammadi, M., Sedighi, M., Hemmati-Sarapardeh, A. (2019): Application of nanofluids in enhanced oil recovery: A systematic literature review and organizing framework. Nanofluids and Their Engineering Applications, 433-451. doi: 10.1201/9780429468223-20

Muskus, N., Falta, R. W. (2018): Semi-analytical method for matrix diffusion in heterogeneous and fractured systems with parent-daughter reactions. Elsevier B.V, 94-109 p. doi: $10.1016 /$ j.jconhyd.2018.10.002 
National Research Council (2005): Contaminants in the subsurface: source zone assessment and remediation. National Academies Press, Washington, 370 p. doi: 10.17226/11146

Parker, B. L., Chapman, S. W., Guilbeault, M. A. (2008): Plume persistence caused by back diffusion from thin clay layers in a sand aquifer following TCE source-zone hydraulic isolation. Journal of Contaminant Hydrology, 102, 1-2, 86-104. doi: 10.1016/j.jconhyd.2008.07.003

Parker, B. L., Cherry, J. A., Chapman, S. W. (2004): Field study of TCE diffusion profiles below DNAPL to assess aquitard integrity. Journal of Contaminant Hydrology, 74, 1-4, 197-230. doi: 10.1016/j.jconhyd.2004.02.011

Pinder, G. F., Celia, M. A. (2006): Subsurface hydrology. John Wiley \& Sons, New Jersey, 1-468 p. doi: 10.1002/0470044209

Pulvirenti, M., Tirozzi, B. (1973): Time evolution of a quantum lattice system. Communications in Mathematical Physics, 30, 2, 83-98. doi: 10.1007/BF01645974

Safari, M., Rahimi, A., Gholami, R., Permana, A., Siaw Khur, W. (2020): Underlying mechanisms of shale wettability alteration by low salinity water injection (LSWI). Journal of Dispersion Science and Technology, 1-9. doi: 10.1080/01932691.2020.1813156

Safari, M., Mohammadi, M., Sedighi, M. (2017): Effect of neglecting geothermal gradient on calculated oil recovery. Journal of Applied Geophysics, 138, 33-39. doi: 10.1016/j. jappgeo.2017.01.006

Safari, M., Gholami, R., Khajehvandi, E., Mohammadi, M. (2020): Temperature profile estimation: A study on the Boberg and Lantz steam stimulation model. Petroleum, 6, 1, 92-97. doi: 10.1016/j.petlm.2019.07.002

Sale, T., Newell, C. J. (2010):, Impacts of source management on chlorinated solvent plumes., In Situ Remediation of Chlorinated Solvent Plumes. doi: 10.1007/978-1-44191401-9_7

Shan, X., Chen, H. (1993): Lattice boltzmann model for simulating flows with multiple phases and components. Physical Review E, 47, 3, 1815-1819. doi: 10.1103/PhysRevE.47.1815

Shiri, Y., Hassani, H. (2021): Two-component fluid front tracking in fault zone and discontinuity with permeability heterogeneity. Rudarsko-geološko-naftni zbornik, 36, 3, 19-30. doi: 10.17794/rgn.2021.3.2

Shiri, Y., Shiri, A. (2021): Numerical investigation of fluid flow instabilities in pore-scale with Heterogeneities in permeability and wettability. Rudarsko-geološko-naftni zbornik (The Mining-Geological-Petroleum Bulletin), 36, 3, 143-156. doi: 10.17794/rgn.2021.3.10

Shiri, Y., Hassani, H., Nazari, M., Sharifi, M. (2018): The effects of grain geometry on waterflooding and viscous fingering in micro-fractures and porous media from a lattice Boltzmann method study. Molecular Simulation, 44, 9, 708-721. doi: 10.1080/08927022.2018.1439585

Stroo, H. F., Unger, M., Ward, C. H., Kavanaugh, M. C., Vogel, C., Leeson, A., Marqusee, J. A., Smith, B. P. (2003): Remediating chlorinated solvent source zones. Environmental Science and Technology, 37, 11, 224A-230A. doi: 10.1021/es032488k

Sukop, M., Anwar, S., Lee, J., Cunningham, K., Langevin, C. (2008): Modeling ground-water flow and solute transport in karst with lattice Boltzmann methods. Proceedings of the US Geological Survey Karst Interest Group Workshop, Bowling Green, 77-86.

Sukop, M. C., Huang, H., Alvarez, P. F., Variano, E. A., Cunningham, K. J. (2013): Evaluation of permeability and non-darcy flow in vuggy macroporous limestone aquifer samples with lattice boltzmann methods. Water Resources Research, 49, 1, 216-230. doi: 10.1029/2011WR011788

Sukop, M. C., Thorne, D. T. (2006): Lattice boltzmann modeling: An introduction for geoscientists and engineers. Springer, New York, 1-172 p. doi: 10.1007/978-3-54027982-2

Veinović, Ž., Uroić, G., Domitrović, D., Kegel, L. (2020): Thermo-hydro-mechanical effects on host rock for a generic spent nuclear fuel repository. Rudarsko Geolosko Naftni Zbornik, 35, 1, 65-80. doi: 10.17794/rgn.2020.1.6

Wilson, J. L. (1997): Removal of aqueous phase dissolved contamination: Non-chemically enhanced pump-and-treat. Subsurface Restoration, 17, 271-285.

Zhang, J. (2011): Lattice Boltzmann method for microfluidics: Models and applications. Microfluidics and Nanofluidics, 10, 1, 1-28. doi: 10.1007/s10404-010-0624-1 


\section{SAŽETAK}

\section{Simulacija sanacije vodonosnika slabopropusnih leća fenomenom povratne difuzije}

Protjecanje fluida kroz medije s dvostrukom propusnošću bitno je kod proučavanja transporta otopljene tvari u rudarstvu ili kroz vodonosnik. U ovome radu, s pomoću metode Boltzmannove rešetke, istraženo je ispiranje vodom medija dvostruke propusnosti koji sadržava sitnozrnate leće različite geometrije. Metoda Boltzmannove rešetke u ovome istraživanju uključivala je korištenje modela $\mathrm{D}_{2} \mathrm{Q}_{9} \mathrm{~s}$ vremenom otpuštanja 1 te vrijednošću kohezije 3 za fluid gustoće 1 (mu. $\left.\mathrm{Lu}^{-3}\right)$. Medij dvostruke propusnosti zasićen je fluidom koji je ujedno predstavljao i zagađivač koji se obično zadržavao u slabopropusnim lećama iz kojih se širio nakon ispiranja poroznoga medija sekundarnim fluidom (vodom). Ova je pojava prevladavajuća u slučaju kada istiskujući fluid ima manju koncentraciju od kontaminiranoga fluida, a difuzija i advekcija dva su osnovna mehanizma koja kontroliraju tok fluida kroz šupljikavu sredinu. Rezultati simulacije pokazuju da: (1) advekcija kontrolira transport otopljene tvari tijekom faze ispiranja, dok se povratna difuzija odvija nakon promjene $u$ fazi; (2) geometrija leća utječe na oblik toka i proces sanacije. Rezultat je strategija sanacije vodonosnika bazirana na geometriji i propusnosti leća koja može pomoći u zaštiti okoliša.

\section{Ključne riječi:}

metoda Boltzmannove rešetke, povratna difuzija zagađenja, slabopropusne leće, sanacija vodonosnika, medij s dvostrukom propusnošću

\section{Author's contribution}

Mojtaba Dehqani Tafti (Student, PhD, Mining Engineering) provided the interpretations and wrote the manuscript. Faramarz Doulati Ardejani (Professor, PhD, Mining Engineering) provided the interpretations and the presentation of the results. Mohammad Fatehi Marji (Professor, PhD, Mining Engineering) provided the interpretations and the presentation of the results. Yousef Shiri (Assistant Professor, PhD, Petroleum Engineering) provided the numerical code and some analyses. 